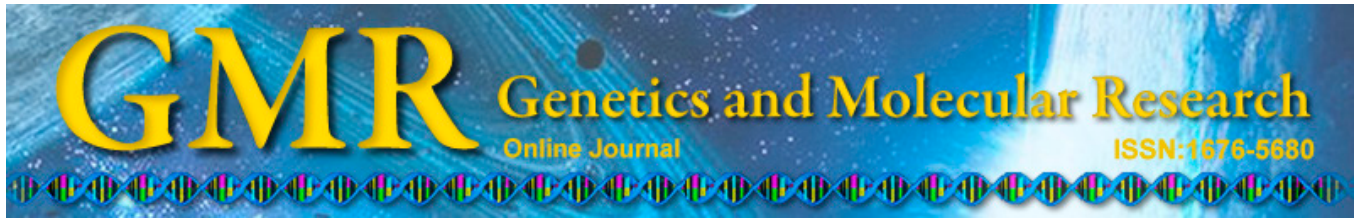

\title{
Effect of CYP3A5 gene polymorphisms on tacrolimus concentration/dosage ratio in adult liver transplant patients
}

\author{
L. Wang ${ }^{1}$, L.H. Liu ${ }^{2}$, W.H. Tong ${ }^{2}$, M.X. Wang ${ }^{3}$ and S.C. Lu ${ }^{4}$ \\ ${ }^{1}$ Department of Surgery and Liver Transplantation Center, \\ Capital Medical University Affiliated to Youan Hospital, Beijing, China \\ ${ }^{2}$ Department of Pharmacy, Liberation Army Secondary Artillery Hospital, \\ Beijing, China \\ ${ }^{3}$ Department of Pharmacy, \\ Capital Medical University affiliated to Youan Hospital, Beijing, China \\ ${ }^{4}$ Department of Hepatobiliary Surgery, General Hospital of PLA, Beijing, China \\ Corresponding author: S.C. Lu \\ E-mail: ShichunLudoc@126.com
}

Genet. Mol. Res. 14 (4): 15148-15157 (2015)

Received June 14, 2015

Accepted September 29, 2015

Published November 25, 2015

DOI http://dx.doi.org/10.4238/2015.November.25.3

\begin{abstract}
We examined the influence of the cytochrome P450 3A5 (CYP3A5) genes in both donors and recipients on the concentrationdosage ratio (C/D) of tacrolimus in Chinese liver transplant patients. Fifty-one adult liver transplant patients who received tacrolimus were included in this study. The CYP $3 A 5$ polymorphism in donors and recipients was determined at the time of transplantation, and tacrolimusbased immunosuppressive therapy was started based on each patient's genetic constitution. The relationship between the $\mathrm{C} / \mathrm{D}$ of tacrolimus for 3 months after surgery and the $C Y P 3 A 5$ genotype was analyzed. A stepwise regression model was used to analyze the relationship between C/D of tacrolimus and genotype, time course, age, and liver weight in liver transplant patients. Three months after liver transplantation, C/D was both affected by the CYP3A5 genotype of both the donors and
\end{abstract}


the recipients. The $\mathrm{C} / \mathrm{D}$ of tacrolimus in patients with the $C Y P 3 A 5^{*} 1$ allele or carrying $C Y P 3 A 5^{*} 1$ allele in the liver was lower than that in $C Y P 3 A 5^{*} 3 / * 3$ patients with the CYP $3 A 5^{*} 3 / * 3$ genotype in the liver (P $<0.01$ ). The $C Y P 3 A 5^{*} 1$ genotype in donors as well as in patients both contributes to interindividual variation in the $\mathrm{C} / \mathrm{D}$ of tacrolimus in adult liver transplantation.

Key words: Cytochrome P450 3A5; Liver transplantation; Tacrolimus; Pharmacogenomics

\section{INTRODUCTION}

Recent studies have shown that blood FK506 (tacrolimus) level is significantly correlated with polymorphismsin the cytochrome P450 3A5 (CYP3A5) gene in the heart, lung, and kidney of transplant patients (Hesselink et al., 2003; Zheng et al., 2003, 2004; Macphee et al., 2005). Mutations in intron 3 of $C Y P 3 A 5(\mathrm{~A} 6986>\mathrm{G})$ results in the production of an inactive enzyme and patients with a specific $C Y P 3 A 5$ polymorphism showed slow tacrolimus metabolism (Kuehl et al., 2001; Lin et al., 2002; Kamdem et al., 2005).

However, in liver transplant patients, the effects are more complicated. CYP $3 A 5$ is expressed both in the liver and small intestine, and thus both the donor and recipient CYP $3 A 5$ genotypes affect tacrolimus metabolism. Few studies have examined the relationship between the CYP3A5 polymorphism and tacrolimus level in liver transplant patients. Moreover, the findings from these studies are inconsistent: some results showed that the receptor genotype has important implications for the metabolism of tacrolimus (Li et al., 2013; Spierings et al., 2013; Zhang et al., 2013), while other studies showed that blood tacrolimus level is more closely associated with the donor genotype (Barry and Levine, 2010; De Jonge et al., 2012; Valente et al., 2013).

Thus, we performed a prospective study to identify the genotype with the most significant effect on tacrolimus metabolism. Before transplantation, we investigated the genotypes of donors and recipients and adjusted the dosage based on each patient's genetic constitution to determine a target trough concentration. A 3-month follow-up after transplantation was performed to investigate the association between the concentration/dosage $(\mathrm{C} / \mathrm{D})$ ratio of tacrolimus and the CYP $3 A 5$ status of donors as well as of recipients.

In addition, because CYP $3 A 5$ is expressed in both the liver and small intestinal epithelium, we hypothesized that in recipients who received organs from donors with different CYP3A5 genotypes, the ratio of liver weight between the donor and recipient (donor/recipient) may be of clinical significance to the plasma C/D ratio of tacrolimus. Stepwise regression analysis was performed to investigate the influence of liver weight, CYP3A5 genotype, time course, and age on the tacrolimus $\mathrm{C} / \mathrm{D}$ ratio.

\section{MATERIAL AND METHODS}

\section{Patients}

From November 2010 to November 2011, 60 Chinese adult patients underwent orthotopic liver transplantation (OLT) in our center. We determined the CYP3A5 genotype of the 
recipient and corresponding donor before operation. The condition of 4 patients was not stable and these patients died from graft dysfunction, severe infection, and cerebral hemorrhage within 3 months after liver transplantation. Five patients were excluded because they did not attend regular out-patient visits. A total of 51 patients were enrolled in the study. In addition, patients with concentration values influenced by therapy with potential inducers or inhibitors of the CYP enzyme, such as rapamus and fluconazole, were excluded.

\section{Genotype analysis}

Peripheral blood samples from recipients and their corresponding donors were obtained before operation. Genomic DNA was extracted using the MagNA Pure LC DNA Isolation kit I (Roche, Mannheim, Germany). The single-nucleotide polymorphism A6986G in the CYP3A5 intron 3 was identified using the polymerase chain reaction (PCR)-restriction fragment length polymorphism method.

Primer sequences were as follows: forward 5'-CAT CAG TTA GAT GAC AGA TGA-3' and reverse 5'-GGT CCA AAC AGG GAA GAAATA-3'. PCR was performed in a volume of 50 $\mu \mathrm{L}$ containing $0.2 \mu \mathrm{M}$ of each primer, $0.2 \mathrm{mM}$ dNTPs, 10X PCR buffer, $2.5 \mathrm{mM} \mathrm{MgCl}$, and $0.6 \mathrm{U} \mathrm{Taq}$ DNA polymerase. The PCR was carried out as follows: $10 \mathrm{~min}$ at $94^{\circ} \mathrm{C}, 32$ cycles for $45 \mathrm{~s}$ at $94^{\circ} \mathrm{C}, 45 \mathrm{~s}$ at $58^{\circ} \mathrm{C}$, and $45 \mathrm{~s}$ at $72^{\circ} \mathrm{C}$, and finally $10 \mathrm{~min}$ at $72^{\circ} \mathrm{C}$. The 293 -base pair PCR product was electrophoresed on a $1.5 \%$ agarose gel and subsequently obtained using the Qiaquick Gel Extraction Kit (Qiagen, Hilden, Germany). For restriction digestion, a $20-\mu \mathrm{L}$ volume including $6 \mu \mathrm{L} \mathrm{PCR}$ product and $0.5 \mathrm{U} \mathrm{SspI} \mathrm{enzyme} \mathrm{was} \mathrm{incubated} \mathrm{at} 37^{\circ} \mathrm{C}$ overnight. The digestion product was electrophoresed on a $15 \%$ polyacrylamide gel followed by silver staining for genotype determination.

\section{Immunosuppressive therapy}

Before operation, the CYP $3 A 5$ genotype of each patient and corresponding donor was identified. After operation, the tacrolimus dosage was determined based on each patient's condition, as well as the recipient and donor genetic constitutions. Tacrolimus (Prograf, Astellas Pharma Inc., Tokyo, Japan) was orally administered twice daily (at 6:00 a.m. and 6:00 p.m.). The mean initial dosage of tacrolimus in patients with $C Y P 3 A 5 * 1 / * 1(* 1 / * 3)$ was $4-6 \mathrm{mg}$ per day, and the mean initial dosage of tacrolimus in patients with $C Y P 3 A 5^{*} 3 / * 3$ was $2-4 \mathrm{mg}$ per day. The target blood trough concentration was $6-8 \mathrm{ng} / \mathrm{mL}$. The dosage was adapted based on clinical syndromes, trough concentration level, renal function, and immune function; special consideration of the dose was made when administering tacrolimus to patients with the CYP $3 A 5^{*} 3 / * 3$ genotype and $C Y P 3 A 5^{*} 3 / * 3$ liver status. In addition, $1 \mathrm{~g}$ methylprednisolone was administered intravenously during operation and the dosage was gradually reduced. Oral prednisolone replaced methylprednisolone 1 week after surgery and the dosage was gradually tapered off over the 3 months after the transplant. Before transplantation, $500 \mathrm{mg}$ mycophenolate mofetil was administered orally, and then administered at $1000 \mathrm{mg}$ per day.

\section{Tacrolimus concentration}

A total of 357 blood samples were collected before the morning dose (at 8:00 a.m.) on the day of $1,2,3,4,5,6,7,8$, and 12 weeks after transplantation. Tacrolimus concentra- 
tion $(\mathrm{ng} / \mathrm{mL})$ was assayed using a microparticle enzyme immunoassay method with an IMx analyzer (Abbott Laboratories; Abbott Park, IL, USA) on the day of blood collection. The daily dose of tacrolimus was recorded and its weight-adjusted dosage $\left(\mathrm{mg} \cdot \mathrm{kg}^{-1} \cdot \mathrm{day}^{-1}\right)$ was calculated.

\section{Statistical analysis}

All values are reported as means \pm standard deviation. The $C Y P 3 A 5^{*} 1 / * 1$ genotype and $* 1 / * 3$ genotype were combined into the expresser genotype group and the $* 3 / * 3$ genotype was considered the nonexpresser group. The chi-square test was used to compare the distribution of genotypes (constituent ratio) in recipients and donors. Intergroup differences in the $\mathrm{C} / \mathrm{D}$ ratio of tacrolimus were analyzed using the Mann-Whitney U-test (2-group) and the Kruskal-Wallis tests (4-group). Stepwise regression analysis was used to investigate the influence of liver weight, CYP $3 A 5$ genotype, time course post-operation, and age on the tacrolimus C/D ratio. Statistical analyses were performed using the statistical software package SPSS13.0 (SPSS, Inc., Chicago, IL, USA). A P value less than 0.05 was considered to be statistically significant.

\section{RESULTS}

\section{Patient data}

A total of 51 patients (39 men and 12 women) were enrolled in the study. Demographic data of the study population are shown in Table 1 . The mean recipient age was 51.65 \pm 8.53 (26-73) years and the mean recipient body weight was $69.73 \pm 12.63(45-105) \mathrm{kg}$. The most common primary disease leading to liver transplantation was hepatitis B virus infection (33/51, 64.7\%). A few patients supplied insufficient samples during follow-up, and the drug concentration data for most patients were included.

Table 1. Characteristics of the study population $(\mathrm{N}=51)$.

\begin{tabular}{lc}
\hline Characteristics & \\
\hline Demographics & $39 / 12$ \\
Gender (male/female) & $51.65 \pm 8.53(26,73)$ \\
Age (year) & $69.73 \pm 12.63(45-105)$ \\
Body weight (kg) & $1327.35 \pm 277.69(880-2190)$ \\
Graft weight (g) & $1.95 \pm 0.43(1.08-2.88)$ \\
Graft-to-recipient weight ratio (\%) & 38 \\
Primary disease & 19 \\
Cirrhosis & 5 \\
Cancer & 33 \\
Hepatitis C virus infection & 8 \\
Hepatitis B virus infection & 1 \\
Primary biliary cirrhosis & 2 \\
Alcoholic cirrhosis & 379 \\
Others (drug induced liver injury) & $7(5-9)$ \\
Concentration data of tacrolimus & $0.065 \pm 0.023(0.013-0.136)$ \\
Number of samples & $5.63 \pm 3.37(0.5-18.7)$ \\
Number of samples per patient & \\
Dose (mg/day/kg) & \\
Trough concentration (ng/mL) & \\
\hline
\end{tabular}

Data are reported as a number or median (range). 


\section{Blood tacrolimus concentrations}

The blood tacrolimus concentration is shown in Figure 1, and data from the same patient are connected with a line. Tacrolimus concentration ranged from $0.5-18.7 \mathrm{ng} / \mathrm{mL}$.

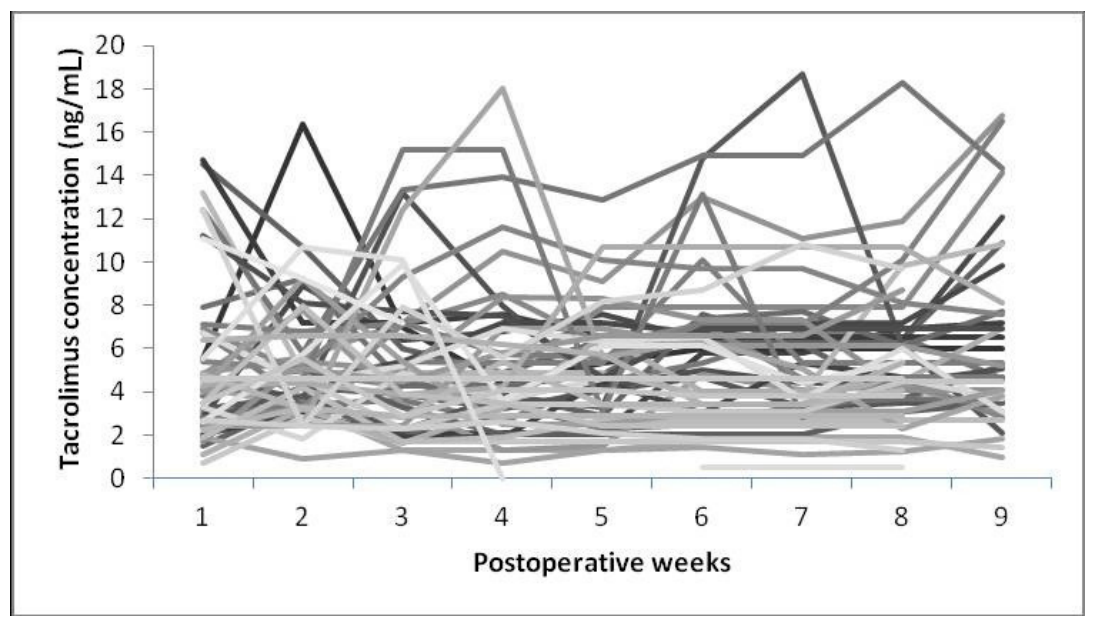

Figure 1. Tacrolimus trough concentrations $v s$ postoperative weeks for all recipients $(\mathrm{N}=51)$.

\section{Genotype data}

The genotype frequencies of the CYP $3 A 5^{*} 3$ polymorphisms in both donors and recipients are summarized in Table 2 . Among the 51 liver transplant recipients and their corresponding donors, $6(11.8 \%)$ recipients and $4(7.8 \%)$ donors exhibited the $* 1 / * 1$ genotype, $19(37.3 \%)$ recipients and $24(47.1 \%)$ donors carried $* 1 / * 3$, and $26(51.0 \%)$ recipients and $23(45.1 \%)$ donors carried $* 3 / * 3$. Therefore, the distribution frequency was $9.8 \%$ with $* 1 / * 1$, $42.2 \%$ with $* 1 / * 3$, and $48.0 \%$ with $* 3 / * 3$; the allelic frequencies of $C Y P 3 A 5 * 1$ and $* 3$ were $30.9 \%(63 / 204)$ and $69.1 \%(141 / 204)$, respectively. The genotype proportions showed no statistically significant difference between recipients and donors $(\mathrm{P}>0.05)$.

Table 2. Pharmacogenomic data for the study population $(\mathrm{N}=51)$.

\begin{tabular}{lrc}
\hline Genotype frequency & Recipient & Donor \\
\hline CYP3A5*1/*1 & $6(11.8 \%)$ & $4(7.8 \%)$ \\
CYP3A5*1/*3 & $19(37.3 \%)$ & $24(47.1 \%)$ \\
CYP3A5*3/*3 & $26(51.0 \%)$ & $23(45.1 \%)$ \\
\hline
\end{tabular}

Data are reported as the number of patients (percent) for genotype frequency.

\section{Influence of pharmacogenomic data on tacrolimus C/D}

To investigate the contribution of pharmacogenomic data on $\mathrm{C} / \mathrm{D}$, we divided patients into 2 groups based on patient and donor genotypes. Individuals with $1 C Y P 3 A 5^{*} 1$ allele (A at position 6986) produced high levels of full-length CYP $3 A 5 \mathrm{mRNA}$ and expressed CYP3A5 protein (Kuehl et al., 2001). Thus, we combined patients with the $C Y P 3 A 5^{*} 1 / * 1$ genotype and 
$* 1 / * 3$ genotype into the expresser genotype group and the *3/*3 genotype as the nonexpresser group. Table 3 shows the tacrolimus C/D ratio of the groups. Age, gender, weight, and liver weight showed no significant difference between groups.

For the donorCYP $3 A 5$ genotype, lower tacrolimus $\mathrm{C} / \mathrm{D}$ ratios were observed among recipients receiving $C Y P 3 A 5^{*} 1$ allele-carrying organs compared with recipients receiving non-CYP3A5*1allele-carrying organs at all 9 time points after OLT $(\mathrm{P}<0.05)$ (Figure 2). For the recipient genotype, after 2 weeks, the C/D ratio in $* 1 / * 1(* 1 / * 3)$ genotype patients was significantly lower than that in $* 3 / * 3$ genotype patients after 2 weeks (Figure 3).

We then reviewed the data and divided the patients into 4 groups according to $C Y$ P3A5 allelic status, and the tacrolimus $\mathrm{C} / \mathrm{D}$ ratio was compared among groups (Table 4).

As shown in Figure 3, at 2, 3, 4, 5, 6, 7, 8, and 12 weeks post-operation, both the graft and recipient $C Y P 3 A 5^{*} 3$ polymorphisms played an important role in the variability of tacrolimus $\mathrm{C} / \mathrm{D}$.

Table 3. Tacrolimus concentration/dosage post-transplant according to donor's and recipient's CYP3A5 genotype.

\begin{tabular}{|c|c|c|c|c|c|c|}
\hline \multirow{2}{*}{$\begin{array}{l}\mathrm{C} / \mathrm{D} \text { ratio } \\
(\mathrm{ng} / \mathrm{mL}) /(\mathrm{mg} / \mathrm{kg} / \text { day })\end{array}$} & \multicolumn{3}{|c|}{ Donor } & \multicolumn{3}{|c|}{ Recipient } \\
\hline & $* 3 / * 3(\mathrm{~N}=25)$ & $* 1 / * 1, * 1 / * 3(\mathrm{~N}=26)$ & $P$ & $* 3 / * 3(\mathrm{~N}=25)$ & $* 1 / * 1, * 1 / * 3(\mathrm{~N}=26)$ & $\mathrm{P}$ \\
\hline Week 1 & $111.02 \pm 61.19$ & $71.20 \pm 42.42$ & 0.021 & $100.62 \pm 66.44$ & $77.23 \pm 48.57$ & 0.157 \\
\hline Week 2 & $107.30 \pm 63.37$ & $76.17 \pm 44.71$ & 0.046 & $99.12 \pm 58.64$ & $80.95 \pm 51.79$ & 0.246 \\
\hline Week 3 & $116.92 \pm 62.28$ & $64.43 \pm 36.17$ & 0.002 & $109.37 \pm 62.48$ & $65.99 \pm 43.39$ & 0.006 \\
\hline Week 4 & $115.72 \pm 68.76$ & $65.91 \pm 43.54$ & 0.006 & $112.18 \pm 69.65$ & $61.25 \pm 34.19$ & 0.002 \\
\hline Week 5 & $105.45 \pm 50.12$ & $61.81 \pm 28.81$ & 0.001 & $98.21 \pm 49.02$ & $62.40 \pm 31.39$ & 0.004 \\
\hline Week 6 & $102.39 \pm 64.84$ & $70.68 \pm 34.99$ & 0.002 & $123.94 \pm 56.79$ & $60.62 \pm 32.54$ & 0.000 \\
\hline Week 7 & $114.92 \pm 59.98$ & $73.10 \pm 41.70$ & 0.008 & $119.73 \pm 56.51$ & $62.66 \pm 33.34$ & 0.000 \\
\hline Week 8 & $118.85 \pm 57.49$ & $79.77 \pm 51.91$ & 0.016 & $123.46 \pm 57.65$ & $69.88 \pm 43.12$ & 0.001 \\
\hline Week 12 & $158.55 \pm 78.43$ & $76.39 \pm 48.53$ & 0.001 & $132.06 \pm 77.52$ & $86.51 \pm 64.47$ & 0.053 \\
\hline
\end{tabular}

Data are reported as means $\pm \mathrm{SD}$. C/D, dose-adjusted trough blood concentration. $\mathrm{P}<0.05$, significant difference in the mean value from the CYP $3 \mathrm{~A} 5 * 3 / * 3$ group (unpaired $t$-test).

A

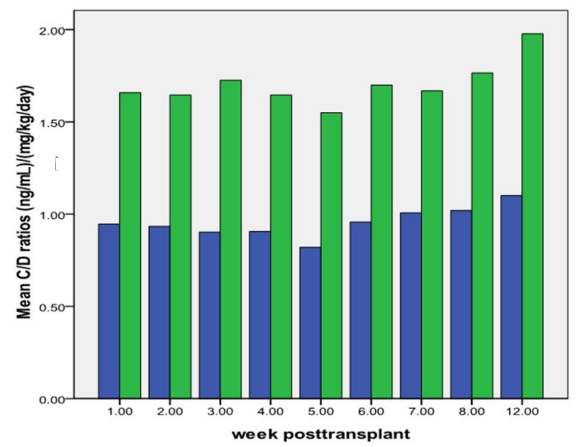

B

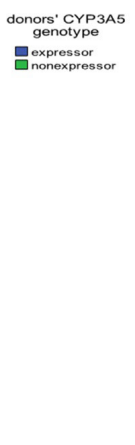

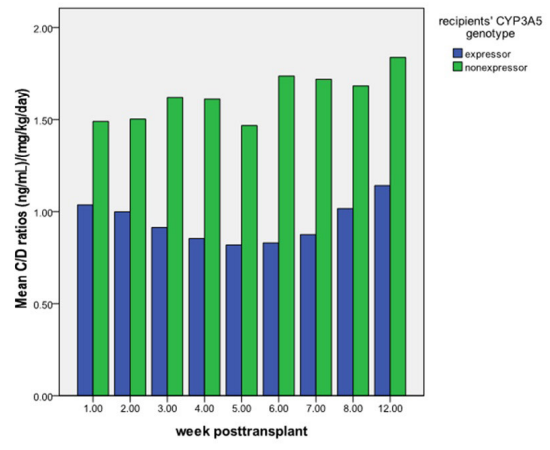

Figure 2. Influence of donor and recipient genotypes on the tacrolimus $\mathrm{C} / \mathrm{D}$ ratio for 3 months after orthotopic liver transplantation (OLT). A. Influence of donor genotype on the tacrolimus C/D ratio for 3 months after OLT. B. Influence of recipient genotype on the tacrolimus C/D ratio for 3 months after OLT. Each bar indicates the median value. ${ }^{*} \mathrm{P}<0.05$, significant difference between 2 groups (Mann-Whitney U-test). 


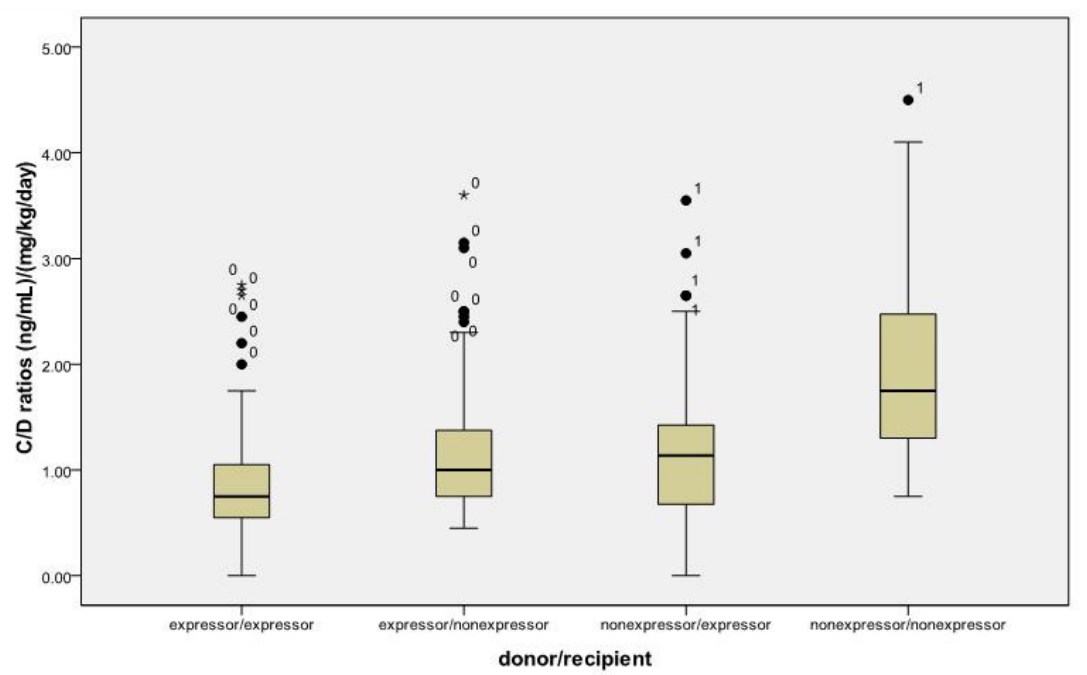

Figure 3. Tacrolimus C/D ratio of the 4 groups by genotype of grafts and recipients.

Table 4. Tacrolimus blood $\mathrm{C} / \mathrm{D}$ ratios $(\mathrm{ng} / \mathrm{mL}) /(\mathrm{mg} / \mathrm{kg} /$ day) in different groups of combined CYP3A5 genotypes in both donor and recipient at $1,2,3,4,5,6,7,8,12$ weeks post-transplantation.

\begin{tabular}{|c|c|c|c|c|}
\hline \multicolumn{5}{|l|}{$\mathrm{C} / \mathrm{D}$ ratios } \\
\hline Donor & $* 1 / * 1$ and $* 1 / * 3$ & $* 1 / * 1$ and $* 1 / * 3$ & $* 3 / * 3$ & $* 3 / * 3$ \\
\hline Recipient & $* 1 / * 1$ and $* 1 / * 3$ & $* 3 / * 3$ & $* 1 / * 1$ and $* 1 / * 3$ & $* 3 / * 3$ \\
\hline $\mathrm{N}$ & 17 & 11 & 8 & 15 \\
\hline Week 1 & $79.76 \pm 49.50$ & $70.63 \pm 37.69$ & $83.46 \pm 59.86$ & $120.01 \pm 63.41$ \\
\hline Week 2 & $80.21 \pm 50.96 *$ & $57.26 \pm 18.77 *$ & $70.90 \pm 45.66^{*}$ & $132.42 \pm 71.20$ \\
\hline Week 3 & $60.95 \pm 34.06^{*}$ & $69.81 \pm 40.29 *$ & $76.69 \pm 60.09 *$ & $138.39 \pm 60.66$ \\
\hline Week 4 & $56.31 \pm 32.33^{*}$ & $79.88 \pm 54.77 *$ & $72.55 \pm 38.20 *$ & $135.87 \pm 71.41$ \\
\hline Week 5 & $58.15 \pm 29.89^{*}$ & $67.14 \pm 27.68^{*}$ & $72.11 \pm 34.94 *$ & $121.00 \pm 49.29$ \\
\hline Week 6 & $53.76 \pm 25.10^{*}$ & $95.29 \pm 33.38^{*}$ & $74.34 \pm 42.51 *$ & $144.95 \pm 62.01$ \\
\hline Week 7 & $53.98 \pm 23.33^{*}$ & $100.91 \pm 47.63^{*}$ & $80.00 \pm 44.40 *$ & $133.54 \pm 60.00$ \\
\hline Week 8 & $62.97 \pm 34.49^{*}$ & $104.20 \pm 64.13 *$ & $83.72 \pm 56.84^{*}$ & $137.58 \pm 49.97$ \\
\hline Week 12 & $73.60 \pm 59.87^{*}$ & $79.75 \pm 33.03^{*}$ & $117.48 \pm 71.18^{*}$ & $175.66 \pm 77.58$ \\
\hline
\end{tabular}

\section{Influence of age, time course, and graft liver weight on the $C / D$ of tacrolimus}

To investigate the influence of age, time course, and graft liver weight on the C/D of tacrolimus, stepwise regression analysis was performed. The $\mathrm{C} / \mathrm{D}$ of tacrolimus was considered to be the dependent variable $(\mathrm{Y})$, while 6 factors, including age, gender, graft liver weight, time-course after operation, and donor and recipient CYP $3 A 5$ genotypes, were considered independent variables $(\mathrm{X})$. A stepwise regression equation was obtained as follows: $\mathrm{Y}$ (tacrolimus dose-adjusted trough blood concentration) $=1.025+0.625$ (donor CYP $3 A 5$ genotype) +0.520 (recipient CYP3A5 genotype) +0.021 (time course post-transplant) -0.008 (age), $\mathrm{P}<0.01$. Liver weight was not correlated with blood concentrations.

\section{DISCUSSION}

We conducted this prospective study to determine the effects of CYP3A5 genotypes 
of donors and recipients on the $\mathrm{C} / \mathrm{D}$ ratio of tacrolimus after liver transplantation, as well as to analyze the potential influence of graft liver weight, age, and time course after OLT.

Figure 1 shows the pharmacokinetic characteristics of tacrolimus large interindividual variations. Although most blood tacrolimus concentrations were maintained within the therapeutic range $(5-15 \mathrm{ng} / \mathrm{mL})$ during the 3 months after liver transplantation, the tacrolimus concentration ranged by 10 -fold. Therefore, a more optimal and safe tacrolimus dosage program can be established by using pharmacogenomic information as well as clinical data.

Some previous studies in renal, lung, and heart transplantation have confirmed the contribution of the CYP $3 A 5$ polymorphism to individual differences in the response to tacrolimus (Hesselink et al., 2003; Zheng et al., 2003, 2004; Macphee et al., 2005; De Jonge et al., 2012; Li et al., 2013; Spierings et al., 2013; Zhang et al., 2013). However, in liver transplantation, the contribution of donor liver and recipient gut on tacrolimus metabolism increases the complexity of the mechanism of tacrolimus metabolism. Few studies have examined the relationship between the CYP $3 A 5$ polymorphism and variation in tacrolimus individual differences following liver transplantation, and the results are controversial (Barry and Levine, 2010; Valente et al., 2013).

A liver transplantation study of 53 patients by Yu et al. (2006) suggested that the donor $C Y P 3 A 5^{*} 3$ genotype contributes to the large interindividual variation in tacrolimus dose requirement, while the influence of $C Y P 3 A 5$ in the gut is less important. Another study revealed that patients with a liver graft carrying the $C Y P 3 A 5^{*} 1$ allele had a lower C/D ratio of tacrolimus than patients with a $C Y P 3 A 5^{*} 3 / * 3$-carrying grafted liver (Goto et al., 2004). Some studies have demonstrated the contribution of the recipient CYP $3 A 5$ genotype on tacrolimus metabolism. Mancinelli et al. (2001) found that tacrolimus pharmacokinetics were affected by differences of the intestine CYP $3 A 5$ genotype. A significant difference was also found in tacrolimus daily dose and tacrolimus $\mathrm{C} / \mathrm{D}$ ratios between recipients carrying the CYP3A5 6986GG allele and recipients carrying the CYP3A5 6986AG/AA allele both at 2 and 3 weeks and 1 month after transplantation (Uesugi et al., 2006). One previous study found that the genetic polymorphism of CYP3A5 in Chinese patients who underwent liver transplantation is an important factor affecting tacrolimus blood concentration (Jin et al., 2008).

In this study, we investigated $C Y P 3 A 5^{*} 3$ polymorphisms in 51 Chinese liver transplantation donors and recipients. Based on donor genotype, significant differences in the tacrolimus blood C/D ratio were found between the CYP3A5*1/*1(*1/*3) and CYP $3 A 5^{*} 3 / * 3$ groups at all of the time points 3 months after transplantation (Figure 2A). Analysis of recipient genotypes showed similar results (Figure 2B), demonstrating that the genotype of donors and recipients both affect tacrolimus concentration. Although no significant difference was found after the 1 st and 2 nd week post-transplantation, this may be because in early stages after operation, the conditions of the recipients were not stable, and liver and intestine dysfunction resulting from ischemia reperfusion injury had not recovered.

To further validate this hypothesis, we divided the patients into 4 groups by donor and recipient genotype and compared the tacrolimus $\mathrm{C} / \mathrm{D}$ ratio among groups. As shown in Table 4, the tacrolimus $\mathrm{C} / \mathrm{D}$ ratios of the $C Y P 3 A 5$ nonexpressers in both donors and recipients were higher compared with the other 3 groups. No significant difference was found among the other 3 groups regarding tacrolimus $\mathrm{C} / \mathrm{D}$ ratios. Thus, both the hepatic and the intestinal CYP $3 A 5^{*} 1$ allele significantly influenced tacrolimus dose and C/D ratio. Either the donor or recipient with 1 CYP $3 A 5^{*} 1$ allele (A at position 6986) were related to a lower tacrolimus C/D ratio in the 3 months after operation. 
Because most CYP3A5 enzymes are enriched in the intestinal tract and liver, the contribution of the donor liver should be considered when examining the individual variations of tacrolimus pharmacokinetics. In addition, the first-pass elimination of immunosuppressants in the gut is thought to account in part for individual variations (Tuteja et al., 2001; Kamdem et al., 2005; Tang et al., 2011; Ji et al., 2012; Zhao et al., 2013).

In addition, we hypothesized that liver size may be an important factor affecting the contribution of the recipient and donor genotypes (Kishino et al., 2006; Lee et al., 2006; Mochizuki et al., 2006). Thus, we evaluated genotype and non-genotype factors using stepwise regression analysis and found that factors impacting patient tacrolimus blood concentrations in a descending order were: donor $C Y P 3 A 5$ genotype, recipient $C Y P 3 A 5$ genotype, time course, and age. Interestingly, the partial regression coefficient of the liver size was negative, which may be because liver size was similar among these patients. The most important factor affecting tacrolimus blood concentration may change in long-term stages after operation.

In conclusion, our finding suggests that both donor and recipient CYP3A5 polymorphisms affect the C/D of tacrolimus. Donors or recipients with the $C Y P 3 A 5^{*} 1$ genotype were associated with a lower tacrolimus $\mathrm{C} / \mathrm{D}$ ratio for 3 months after operation. Only the $C Y P 3 A 5 * 3 / * 3$ genotype recipients with $C Y P 3 A 5 * 3 / * 3$ liver required lower tacrolimus dosage to achieve the target trough concentration. Multiple factor stepwise regression revealed that the factors impacting the $\mathrm{C} / \mathrm{D}$ of tacrolimus $[(\mathrm{ng} / \mathrm{mL}) /(\mathrm{mg} / \mathrm{kg} /$ day $)]$ were the donor CYP $3 A 5$ genotype, recipient $C Y P 3 A 5$ genotype, time course, and age.

Identification of genetic parameters will enable the establishment of a more optimal and safe tacrolimus dosage to obtain adequate immunosuppression without increasing the risk of toxicity in patients undergoing liver transplant. Further studies are needed to explore the later stages and the clinical effect of adapting tacrolimus dosage by genotype.

\section{ACKNOWLEDGMENTS}

Research supported by the Organ Transplantation Research Fund from the Ministry of Health of China.

\section{REFERENCES}

Barry A and Levine MA (2010). Systematic review of the effect of CYP3A5 genotype on the apparent oral clearance of tacrolimus in renal transplant recipients. Ther Drug Monit. 32: 708-714.

De Jonge H, de Loor H, Verbeke K, Vanrenterghem Y, et al. (2012). In vivo CYP3A4 activity, CYP3A5 genotype, and hematocrit predict tacrolimus dose requirements and clearance in renal transplant patients. Clin. Pharmacol Ther. 92: 366-375.

Goto M, Masuda S, Kiuchi T, Ogura Y, et al. (2004). CYP3A5*1-carrying graft liver reduces the concentration/oral dose ratio of tacrolimus in recipients of livingdonor liver transplantation. Pharmacogenetics 14: 471-478.

Hesselink DA, van Schaik RH, van der Heiden IP, van der Werf M, et al. (2003). Genetic polymorphisms of the CYP3A4, CYP3A5, and MDR-1 genes and pharmacokinetics of the calcineurin inhibitors cyclosporine and tacrolimus. Clin. Pharmacol. Ther. 74: 245-254.

Ji E, Choi L, Suh KS, Cho JY, et al. (2012). Combinational effect of intestinal and hepatic CYP3A5 genotypes on tacrolimus pharmacokinetics in recipients of living donor liver transplantation. Transplantation 94: 866-872.

Jin Z, Zhang WX, Mao AW, Chen H, et al. (2008). Relationship between CYP3A5 and MDR1 gene polymorphism and blood concentration of tacrolimus in Chinese liver transplant patients. Chin. Pharmaceutical. J. 43: 649-653.

Kamdem LK, Streit F, Zanger UM, Brockmöller J, et al. (2005).Contribution of CYP3A5 to the in vitro hepatic clearance of tacrolimus. Clin. Chem. 51: 1374-1381.

Kishino S, Ohno K, Shimamura T, Furukawa H, et al. (2006). A nomogram for predicting the optimal oral dosage of 
tacrolimus in liver transplant recipients with small-for-size grafts. Clin. Transplant. 20: 443-449.

Kuehl P, Zhang J, Lin Y, Lamba J, et al. (2001). Sequence diversity in CYP3A promoters and characterization of the genetic basis of polymorphic CYP3A5 expression. Nat. Genet. 27: 383-391.

Lee JY, Hahn HJ, Son IJ, Suh KS, et al. (2006). Factors affecting the apparent clearance of tacrolimus in Korean adult liver transplant recipients. Pharmacotherapy 26: 1069-1077.

Li DY, Teng RC, Zhu HJ and Fang Y (2013). CYP3A4/5 polymorphisms affect the blood level of cyclosporine and tacrolimus in Chinese renal transplant recipients. Int. J. Clin. Pharmacol. Ther. 51: 466-474.

Lin YS, Dowling AL, Quigley SD, Farin FM, et al. (2002). Co-regulation of CYP3A4 and CYP3A5 and contribution to hepatic and intestinal midazolam metabolism. Mol. Pharmacol. 62: 162-172.

Macphee IA, Fredericks S, Mohamed M, Moreton M, et al. (2005). Tacrolimus pharmacogenetics: the CYP3A5*1 allele predicts low dose-normalized tacrolimus blood concentrations in whites and South Asians. Transplantation 79: 499-502.

Mancinelli LM, Frassetto L, Floren LC, Dressler D, et al. (2001). The pharmacokinetics and metabolic disposition of tacrolimus: a comparison across ethnic groups. Clin. Pharmacol. Ther. 69: 24-31.

Mochizuki N, Matsumoto K, Ohno K, Shimamura T, et al. (2006). Effects of hepatic CYP3A4 activity on disposition of micafungin in liver transplant recipients with markedly small-for-size grafts. Transplant. Proc. 38:3649-3650.

Spierings N, Holt DW and Macphee IA (2013). CYP3A5 genotype had no impact on intrapatient variability of tacrolimus clearance in renal transplant tecipients. Ther. Drug Monit. 35: 328-331.

Tang HL, Xie HG, Yao Y and Hu YF (2011). Lower tacrolimus daily dose requirements and acute rejection rates in the CYP3A5 nonexpressers than expressers. Pharmacogenet. Genomics 21: 713-720.

Tuteja S, Alloway RR, Johnson JA and Gaber AO (2001). The effect of gut metabolism on tacrolimus bioavailability in renal transplant recipients. Transplantation 71: 1303-1307.

Uesugi M, Masuda S, Katsura T, Oike F, et al. (2006). Effect of intestinal CYP3A5 on postoperative tacrolimus trough levels in living-donor liver transplant recipients. Pharmacogenet. Genomics 16: 119-127.

Valente G, Rinaldi L, Sgambato M and Piai G (2013). Conversion from twice-daily to once-daily tacrolimus in stable liver transplant patients: effectiveness in a real-world setting. Transplant. Proc. 45: 1273-1275.

Yu SF, Wu LH and Zheng SS (2006). Genetic factors for individual administration of immunosuppressants in organ transplantation. Hepatobiliary Pancreat. Dis. Int. 5: 337-344.

Zhang JJ, Zhang H, Ding XL, Ma S, et al. (2013). Effect of the P450 oxidoreductase 28 polymorphism on the pharmacokinetics of tacrolimus in Chinese healthy male volunteers. Eur. J. Clin. Pharmacol. 69: 807-812.

Zhao W, Fakhoury M, Baudouin V, Storme T, et al. (2013). Population pharmacokinetics and pharmacogenetics of once daily prolonged-release formulation of tacrolimus in pediatric and adolescent kidney transplant recipients. Eur. $J$. Clin. Pharmacol. 69: 189-195.

Zheng H, Webber S, Zeevi A, Schuetz E, et al. (2003). Tacrolimus dosing in pediatric heart transplant patients is related to CYP3A5 and MDR1 gene polymorphisms. Am. J. Transplant. 3: 477-483.

Zheng H, Zeevi A, Schuetz E, Lamba J, et al. (2004). Tacrolimus dosing in adult lung transplant patients is related to cytochrome P4503A5 gene polymorphism. J. Clin. Pharmacol. 44: 135-140. 